\title{
Acne-specific quality of life questionnaire (Acne-QoL): translation, cultural adaptation and validation into Brazilian-Portuguese language*
}

\author{
Cristhine de Souza Leão Kamamoto ${ }^{1}$ \\ Ediléia Bagatin ${ }^{3}$
}

\author{
Karime Marques Hassun ${ }^{2}$ \\ Jane Tomimori ${ }^{4}$
}

DOI: http://dx.doi.org/10.1590/abd1806-4841.20142172

\begin{abstract}
BACKGROUND: many studies about the psychosocial impact of acne have been reported in international medical literature describing quality of life as a relevant clinical outcome. It is well known that the patient's perception about the disease may be different from the physician's evaluation. Therefore, it is important to use validated instruments that turn the patient's subjective opinion into objective information. OBJECTIVES: to translate into Brazilian-Portuguese language and to culturally adapt a quality of life questionnaire, the Acne-Specific Quality of Life Questionnaire (Acne-QoL), as well as to evaluate its reliability and validity. METHODS: measurement properties were assessed: 1) validity: comparison between severity and Acne-QoL domain scores, correlations between acne duration and Acne-QoL domain scores, and correlation between Acne-QoL domain scores and SF-36 components; 2) internal consistency: Cronbach's $\alpha$ coefficient; 3 ) test-retest reproducibility: intraclass correlation coefficient and Wilcoxon test. RESULTS: Eighty subjects with a mean age of $20.5 \pm 4.8$ years presenting mild $(33.8 \%)$, moderate $(36.2 \%)$ and severe $(30 \%)$ facial acne were enrolled. Acne-QoL domain scores were similar among the different acne severity groups except for role-social domain. Subjects with shorter acne duration presented significant higher scores. Acne-QoL domains showed significant correlations, both between themselves and with SF-36 role-social and mental health components. Internal consistency (0.925-0.952) and test-retest reproducibility were considered acceptable (0.768-0.836). ConCLusIONS: the Brazilian-Portuguese version of the Acne-QoL is a reliable and valid satisfactory outcome measure to be used in facial acne studies.
\end{abstract}

Keywords: Acne vulgaris; Indicators of quality of life; Quality of health care; Quality of life

\section{INTRODUCTION}

Acne vulgaris is probably one of the most common skin conditions affecting the general population, especially teenagers and young adults. ${ }^{1}$ A Brazilian survey revealed that $59.4 \%$ of men and $54 \%$ of women had acne, which means that this is the most prevailing dermatosis at all age ranges from 18 to 55, with a prevalence varying from $70.3 \%$ to $38.1 \%{ }^{1-4}$ It is estimated that, in the United States, 45 million people have acne. Although acne vulgaris does not usually compromise general health, consistent studies have demonstrated that it may cause a negative impact on patient's quality of life, with psychological, social wellbeing, and functional abnormalities such as depression, anxiety, anger, low self-esteem, discomfort with self-appearance, embarrassment, self-consciousness, lowered self-concept, social withdrawal, including sui- cidal ideation, as well as negative influence on school and work performance. Therefore, the assessment of the interaction between acne, emotional issues and psyche is crucial to avoid severe damage..$^{5-12}$ Recent studies have noticed the negative impact of acne on medical students, as well as significant associations between suicidal ideation, mental health problems, social impairment, and adolescents with acne..$^{12-13}$

In a previous case-control study, patients with facial acne reported a greater impact on psychological, social and functional capacity domains of the generic questionnaire Sickness Impact Profile (SIP), when compared to patients without acne. ${ }^{14}$ Some authors have observed that acne causes more impact on mental health than other chronic diseases such as asthma, epilepsy and diabetes when using the Medical

\section{Received on 02.10.2012}

Approved by the Advisory Board and accepted for publication on 23.01.2013.

Work performed at the Departamento de Dermatologia Escola Paulista de Medicina - Universidade Federal de São Paulo (EPM- UNIFESP) - São Paulo (SP), Brasil.

Financial Support: None

Conflict of Interest: None

MD, Dermatologist Collaborator of Department of Dermatology - Universidade Federal de São Paulo - UNIFESP, São Paulo - Brazil.

MD, Dermatologist of Department of Dermatology - Universidade Federal de São Paulo - UNIFESP, São Paulo - Brazil.

MD, PhD, Adjunct Professor, Department of Dermatology - Universidade Federal de São Paulo - UNIFESP, São Paulo - Brazil.

MD, PhD, Associate Professor, Department of Dermatology - Universidade Federal de São Paulo - UNIFESP, São Paulo - Brazil. 
Outcomes Study 36-Item Short Form Health Survey (SF-36). ${ }^{15}$ However, disease-specific scales are more accurate than the generic ones in detecting alterations in individual health status. ${ }^{16,17}$ Several acne-specific psychometric instruments have been developed, such as: Acne Disability Index (ADI) (UK, 1989), AcneSpecific Quality of Life Questionnaire (Acne-QoL) (USA, 1996), Assessment of the Psychological and Social Effects of Acne (APSEA) (UK, 1997), Dermatology-Specific Quality of Life Instrument for Acne (DSQL - AC) (USA, 1997) and Acne Quality of Life (AQOL) (Canada, 1998). ${ }^{18-25}$ The Acne-QoL was the first validated disease-specific questionnaire suitable for use in facial acne clinical trials to have its psychometric properties (reliability, validity and responsiveness) soundly documented. Its development was based on questions suggested by subjects with acne who were evaluated during the item generation, item reduction, and pilot testing.

In the last decades, several efforts have been made to develop psychometric tools to be used as efficacy parameters in randomized and controlled dermatological clinical trials. ${ }^{26-29}$ Authors have been encouraged to use health-related quality of life (HRQoL) measuring scales recommended by the American and European regulatory agencies. . $730^{30}$

There is a paucity of Brazilian data regarding validated acne-specific HRQoL instruments. Taking into account the relevance of globalization and of the information concerning acne-specific HRQoL studies, and based on the rising demand for translated instruments, the purpose of this pioneer study consists of translating and adapting the Acne-QoL into Brazilian-Portuguese language, creating the Brazilian-Portuguese version of the Acne-QoL (Acne-QoL-Br) and providing further evidence of its reliability and validity.

\section{MATERIAL AND METHODS}

Translation and cultural adaptation

The choice for the Acne-QoL was based on the absence, in the Brazilian literature, of acne-specific instruments focusing on clinical and epidemiological trials with a well-founded methodology and whose questions have been generated by subjects' reports.

Initially, the permission to use and translate Acne-QoL was requested to the authors who developed the questionnaire. Furthermore, conditions concerning its translation and use were fulfilled in accordance with authors' orientations and internationally accepted standards. The committee which revised the translations and back-translations analyzed in this study was formed by an English teacher and five bilingual dermatologists, one of them being the principal investigator. The general concept was maintained, as well as the item level of understanding, pri- oritizing the semantic and conceptual equivalences. Finally, approval of the final English and BrazilianPortuguese versions of the Acne-QoL was obtained from the authors.

\section{Study design}

This cross-sectional study was conducted at the Department of Dermatology Clinic in Escola Paulista de Medicina of the Universidade Federal de São Paulo, Brazil. It was approved by the Institutional Review Board of the Escola Paulista de Medicina of the Universidade Federal de São Paulo and has therefore been performed in accordance with Declaration of Helsinki (1964) and Good Clinical Practice. Moreover, all subjects gave their informed consent prior to their inclusion in the study, and the term of informed and voluntary consent was considered adequate and therefore accepted. All patients were recruited as they presented or were referred for facial acne care. The study was carried out from July 2007 to July 2009.

Male and female subjects (13 to 35 years old) with facial acne (classified into mild, moderate or severe, according to the classification proposed by the American Academy of Dermatology) from any race were enrolled. ${ }^{31}$ The subjects answered the Acne-QoL$\mathrm{Br}$ and SF-36 questionnaires at the beginning of the study (baseline visit). Seven days later (second visit), they returned to retest and answered the Acne-QoL-Br prior starting therapy. Subjects who had received acne topical treatment in the last four weeks and/or systemic treatment in the last three months prior to baseline were excluded. The other exclusion criteria are defined in the flowchart (Figure 1).

The Acne-QoL contains 19 questions organized into four domains (self-perception, role-social, roleemotional, and acne symptoms) which refer to facial acne. For all domains, higher scores reflect better HRQoL. The total score varies from zero to 114, distributed as follows: 0- 30 (self-perception), 0-24 (role-social), 0-30 (role-emotional), and 0-30 (acne symptoms).

\section{Reliability}

The internal consistency of the questionnaire at all and every domain was assessed by Cronbach's $\alpha$ coefficient. The presence of redundancy was also evaluated.

The test-retest reproducibility was assessed by the intraclass correlation coefficient (ICC) for each domain and by comparison between subjects' answers at baseline and second visit.

\section{Validity}

The validity of the questionnaire was measured by: i) content validity, ii) discriminative validity, assessed by the comparison between Acne-QoL-Br 


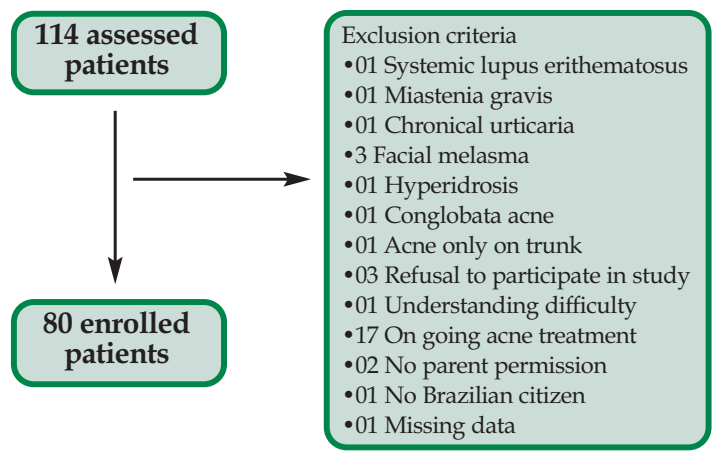

FIGURE 1: Flowchart of the study population $(\mathrm{N}=80)$ and the exclusion criteria

domain scores and facial acne severity using analysis of variance (ANOVA) and by the correlation between Acne-QoL-Br domain scores and acne duration using Pearson's correlation coefficient, and iii) convergent validity, assessed by the evaluation of the correlation of Acne-QoL-Br domain scores with themselves and with SF-36 domain scores using Spearman's correlation coefficient.

\section{Statistical Analysis}

The Kolmogorov-Smirnov normality test was used to evaluate continuous and semi-continuous data. In order to compare groups, chi-square, Student's t (non-paired), Wilcoxon and analysis of the variance (ANOVA) tests were used. As for the evaluation of the degree of association between groups, Pearson's and Spearman's correlation coefficients were used. A probability level equal or lower than 5\% $(p<0.05)$ was considered significant. The sample number was established non-probabilistically. The statistical analysis was performed by the Statistical Package for Social Sciences (SPSS) software, version 13.0 for Windows, SPSS Inc., Chicago, IL).

\section{RESULTS}

Translation and pilot study

The committee evaluated two independent versions translated from English into BrazilianPortuguese, resulting in the first Portuguese version (V1P). This version was submitted to two back-translations that were unified, resulting in the first English language version (V1E). After a pilot test including 22 subjects, some modifications in items 3,14,15,16 and 17 were necessary in the second Portuguese version (V2P). Nevertheless, no significant alteration was observed when comparing V2P to the original English version. The V1E and V2P were analyzed and accepted by the authors of the questionnaire, and the AcneQoL-Br was created (see flowchart on Figure 2).

\section{Study population}

We recruited 114 subjects, but 34 did not fulfill the inclusion and exclusion criteria (Figure 1). The study population comprised 80 subjects $(52.5 \%$ female, $47.5 \%$ male; mean age $20.5 \pm 4.8$ years; mean acne duration $6.6 \pm 4.4$ years) who presented facial acne, as shown in table 1 .

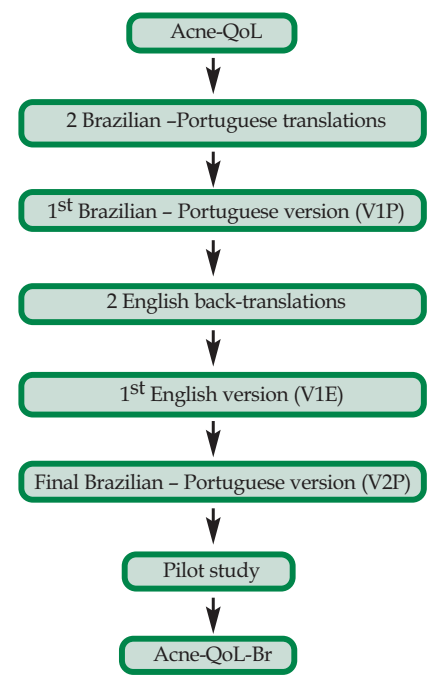

FIGURE 2: Flowchart of the translation and cultural adaptation of the Acne Specific Quality of Life Questionnaire (Acne-QoL) into Brazilian-Portuguese language

TABLE 1: Clinical and demographic characteristics of the study population $(\mathrm{N}=80)$.

\begin{tabular}{lll}
\hline Characteristics & $\mathbf{n}$ & $\%$ \\
Age (years) & & \\
Mean (SD) & $20.5(4.8)$ & \\
Range & $13-35$ & \\
Gender & & \\
Female & 42 & 52.5 \\
Race & & \\
Non-Caucasian & 51 & 64.0 \\
Acne duration (years) & & \\
Mean (SD) & $6.6(4.4)$ & \\
Range & $0.3-21$ & \\
Acne vulgaris classification (AAD) & & \\
Mild & 27 & 33.8 \\
Moderate & 29 & 36.2 \\
Severe & 24 & \\
\hline
\end{tabular}

Legend: $\mathrm{SD}=$ standard deviation; $\mathrm{AAD}=$ American Academy of Dermatology 
Mean Acne-QoL-Br score was $46.86 \pm 22.21$, and mean domain scores were $12.43 \pm 7.19$ (self-perception), $12.28 \pm 6.93$ (role-social), $11.00 \pm 6.60$ (role-emotional), and $11.16 \pm 5.11$ (acne symptoms).

Mean SF-36 domain scores were $93.72 \pm 12.85$ (physical functioning), $89.74 \pm 23.64$ (role-physical), $77.45 \pm 22.00$ (bodily pain), $74.15 \pm 22.97$ (general health), $66.47 \pm 16.77$ (vitality), $71.63 \pm 24.31$ (rolesocial), $67.95 \pm 38.53$ (role-emotional), and $66.87 \pm$ 18+41 (mental health).

Eighty subject responses to Acne-QoL-Br were analyzed at baseline and a total of 42 subjects were retested.

\section{Reliability}

The internal consistency of the 19 Acne-QoL-Br items (Cronbach's $\alpha$ coefficient $=0.925$ ) and of its four domains were considered satisfactory (Table 2). After excluding one question, no significant increase in Cronbach's $\alpha$ coefficient was observed for each item in relation to the whole questionnaire (Table 3). The ICC was considered acceptable in all domains and the response values were similar for subjects who came seven days after baseline to retest (Table 2 and 4).

\section{Validity}

The correlations between SF-36 role-social and mental health components and Acne-QoL-Br domains were considered statistically significant (Table 2). Acne-QoL-Br components showed strong statistically significant correlations, both between themselves and with total Acne-QoL-Br score (Table 5).

\section{Analysis of clinical data}

An analysis of acne duration and severity was performed for all subjects. Mean scores for Acne-QoLBr self-perception, role-emotional and acne symptoms domains were similar in all acne severity groups. However, a significant difference was observed in the role-social domain, since patients with mild facial acne presented higher scores than patients with moderate acne $(\mathrm{p}<0.05)$. No difference in mean scores was observed between patients with mild facial acne and those with severe acne, as well as between patients with moderate acne and those with severe acne (Table 6).

The subjects who experienced shorter acne duration presented significant higher role-emotional and acne symptoms domain scores, as well as marginal correlations between role-social and self-perception domain scores (Table 2).

\section{DISCUSSION}

The purpose of this study was to translate and validate a Brazilian disease-specific instrument for quality of life assessment in acne patients. The results of this study corroborate that the Acne-QoL-Br is a
TABLE 2: Reliability and validity analysis of the final 19-item Acne-QoL-Br

\begin{tabular}{|c|c|c|c|c|c|c|}
\hline & $\mathrm{C}$ & $\mathbf{N}$ & $\begin{array}{c}\text { Self- } \\
\text { perception }\end{array}$ & $\begin{array}{l}\text { Role- } \\
\text { social }\end{array}$ & $\begin{array}{c}\text { Role- } \\
\text { emotional }\end{array}$ & $\begin{array}{c}\text { Acne } \\
\text { symptoms }\end{array}$ \\
\hline $\begin{array}{l}\text { Internal } \\
\text { consistency }\end{array}$ & $\alpha$ & 80 & 0.852 & 0.879 & 0.764 & 0.692 \\
\hline $\begin{array}{l}\text { Test-retest } \\
\text { reproducibility }\end{array}$ & ICC & 42 & 0.836 & 0.782 & 0.795 & 0.768 \\
\hline Content validity & $\alpha$ & 80 & 0.852 & 0.879 & 0.764 & 0.692 \\
\hline $\begin{array}{l}\text { Acne duration } \\
\text { (years) }\end{array}$ & $\mathrm{r}$ & 80 & -0.203 & -0.200 & $-0.333^{*}$ & $-0.241^{*}$ \\
\hline \multicolumn{7}{|c|}{ Convergent validity } \\
\hline $\begin{array}{l}\text { Physical } \\
\text { functioning }\end{array}$ & $\mathrm{R}$ & & 0.186 & 0.106 & -0.017 & 0.082 \\
\hline Role-physical & $\mathrm{R}$ & & 0.064 & 0.064 & -0.168 & -0.207 \\
\hline Bodily pain & $\mathrm{R}$ & & 0.107 & 0.147 & 0.033 & 0.042 \\
\hline General health & $\mathrm{R}$ & & -0.029 & 0.053 & -0.195 & -0.093 \\
\hline Vitality & $\mathrm{R}$ & & 0.134 & 0.208 & 0.086 & 0.036 \\
\hline $\begin{array}{l}\text { Social } \\
\text { functioning }\end{array}$ & $\mathrm{R}$ & & $0.456^{*}$ & $0.386^{*}$ & $0.258^{*}$ & $0.225^{*}$ \\
\hline Role-emotional & $\mathrm{R}$ & & 0.174 & 0.042 & -0.065 & 0.083 \\
\hline Mental health & $\mathrm{R}$ & & $0.265^{*}$ & $0.235^{*}$ & 0.183 & 0.056 \\
\hline
\end{tabular}

Legend: Acne-QoL-Br = Brazilian-Portuguese version of acne-specific quality of life questionnaire; $\mathrm{C}=$ correlation coefficient; $\boldsymbol{\alpha}=$ Cronbach's coefficient; ICC $=$ intraclass correlation coefficient; $\mathbf{r}=$ Pearson's correlation coefficient; $\mathbf{R}=$ Spearman's correlation coefficient.

${ }^{*} \mathrm{p}<0.05$

TABLE 3: Redundancy analysis after the exclusion of one item from the Acne-QoL-Br

\begin{tabular}{ll}
\hline Item & $\boldsymbol{\alpha}$ \\
1 & 0.923 \\
2 & 0.917 \\
3 & 0.920 \\
4 & 0.921 \\
5 & 0.927 \\
6 & 0.919 \\
7 & 0.920 \\
8 & 0.921 \\
9 & 0.924 \\
10 & 0.918 \\
11 & 0.920 \\
12 & 0.918 \\
13 & 0.918 \\
14 & 0.921 \\
15 & 0.925 \\
17 & 0.922 \\
18 & 0.926 \\
19 & 0.922 \\
\hline
\end{tabular}

Legend: Acne-QoL-Br = Brazilian-Portuguese version of acnespecific quality of life questionnaire; $\alpha=$ Cronbach's coefficient 
TABle 4: Comparison of Acne-QoL-Br domain scores between test and retest after seven days without any treatment

\begin{tabular}{llllllll}
\hline Domain & & Test & \multicolumn{3}{l}{ Retest } & p \\
& P25 & Median & P75 & P25 & Median & P75 & \\
Self-perception & 7 & 9 & 14 & 7 & 9 & 20 & 0.063 \\
Role-social & 6 & 9 & 12 & 6 & 10 & 19 & 0.333 \\
Role-emotional & 7 & 9 & 15 & 6 & 13 & 16 & 0.362 \\
Acne symptoms & 7 & 11 & 15 & 11 & 14 & 19 & 0.069 \\
\hline
\end{tabular}

Legend: Acne-QoL-Br = Brazilian-Portuguese version of acnespecific quality of life questionnaire; $\mathbf{P}=$ percentile $\mathrm{p}<0.05$

TABLE 5: Correlations among Acne-QoL-Br domain scores

\begin{tabular}{lcccc}
\hline Domain & $\begin{array}{c}\text { Self- } \\
\text { perception }\end{array}$ & $\begin{array}{l}\text { Role- } \\
\text { social }\end{array}$ & $\begin{array}{c}\text { Role- } \\
\text { emotional }\end{array}$ & $\begin{array}{c}\text { Acne } \\
\text { symptoms }\end{array}$ \\
Self-perception & 1.000 & & & \\
Role-social & $0.714^{*}$ & 1.000 & & \\
Role-emotional & $0.611^{*}$ & $0.526^{*}$ & 1.000 & \\
Acne symptoms & $0.575^{*}$ & $0.573^{*}$ & $0.561^{*}$ & 1.000 \\
Total score & $0.877^{*}$ & $0.858^{*}$ & $0.775^{*}$ & $0.794^{*}$ \\
\hline
\end{tabular}

Legend: Spearman coefficient; ${ }^{*} \mathrm{p}<0.05$

TABlE 6: Descriptive analysis between Acne-QoL-Br domain scores and acne severity according to AAD classification

\begin{tabular}{lccccccccccc}
\hline Domain & \multicolumn{4}{c}{ Mild } & \multicolumn{5}{c}{ Moderate } & \multicolumn{4}{c}{ Severe } & p \\
& N & Mean SD & N & Mean SD & N Mean SD & \\
$\begin{array}{l}\text { Self- } \\
\text { perception }\end{array}$ & 80 & 15 & 8 & 80 & 11 & 7 & 80 & 11 & 6 & 0.168 \\
$\begin{array}{l}\text { Role-social } \\
80\end{array}$ & 15 & 7 & 80 & 10 & 8 & 80 & 12 & 6 & $0.040^{*}$ \\
$\begin{array}{l}\text { Role- } \\
\text { emotional }\end{array}$ & 80 & 11 & 7 & 80 & 11 & 5 & 80 & 11 & 7 & 0.908 \\
$\begin{array}{l}\text { Acne } \\
\text { symptoms }\end{array}$ & 80 & 12 & 5 & 80 & 11 & 6 & 80 & 11 & 5 & 0.584 \\
\hline
\end{tabular}

Legend: Acne-QoL-Br = Brazilian-Portuguese version of acne-specific quality of life questionnaire; AAD = American Academy of Dermatology

${ }^{*} \mathrm{p}<0.05$

reliable and valid instrument to assess HRQoL in facial acne studies.

We followed the translation guidance, cultural adaptation techniques, and psychometric analysis methods suggested by the authors who designed the Acne-QoL and conducted subsequent studies. ${ }^{19-21}$ The questions $3,14,15,16$ and 17 were slightly altered to reach conceptual and semantic equivalences. However, there were no significant structural alterations in the items and in the response numerical scale.

The study population was composed by passive search for subjects with facial acne. This approach may be the reason why our sample did not show the usual distribution as reported in cross-sectional stud- ies concerning severity, age and sex prevalence. . $^{32,33}$

In this study, the Cronbach's $\alpha$ coefficient values reflected an adequate level of internal consistency of the 19 Acne-QoL-Br items, in accordance with Fehnel et al. ${ }^{21}$ The social domain demonstrated the highest equivalence, and the acne symptoms domain score was lower than that of other domains. Although the coefficient was within the expected ranges, the smallest capacity of homogeneity noticed in the acne symptoms domain also occurred in studies that analyzed the measurement properties of the original instrument. ${ }^{21,23,25}$ No redundancy was observed in the Acne-QoL-Br, since there was no significant alteration in Cronbach's $\alpha$ coefficients in the absence of one item.

Thus, in order to obtain a more trustworthy interpretation of instrument stability, Acne-QoL-Br reproducibility was evaluated by the similarity of subject responses at baseline and retest, as described in a previous study. ${ }^{20}$ ICC values presented an acceptable and satisfactory variation, which means that the AcneQoL-Br was considered reproducible. The ICC for the acne symptoms domain showed the lowest value, probably because the items of this domain refer to some aspects which allow a slight variation in subject's perception of facial acne lesions and sequelae. ${ }^{21,24,25}$ This perception may be heightened or lessened. The dynamic and polymorphic behavior of facial acne and the motivation generated from knowing that the treatment would be prescribed after the second interview are factors that need to be taken into account. Such findings indicated that items related to facial acne were stable, since it did not get better or worse during the period between the two interviews. Anderson and Rajagopalan used the ICC to assess test-retest reliability, with an interval from three to seven days, obtaining good results. ${ }^{23}$ Unlike this study, other validation studies of acne-specific questionnaires used Pearson's and Spearman's correlation coefficients to determine test-retest reliability. ${ }^{22,25}$ The ideal interval for retest application of the Acne-QoL$\mathrm{Br}$ was seven days, ratifying the interval established by the original instrument and those used in other studies, i.e., equal or smaller than seven days. ${ }^{19-21,23} \mathrm{~A}$ previous study that used a more comprehensive and complete methodology (including ICC, Pearson's coefficient, and Student's test) was carried out by a French group, but nevertheless included a small group of sixteen subjects. The authors decided to use the Cardiff Acne Disability Index (CADI), which may not be considered gold standard for clinical trials. ${ }^{34}$

During the validation phase of this study, a lack of correlation between facial acne severity and quality of life was observed, confirming the results from Martin et al, except for the Acne-QoL-Br role-social domain, in which subjects with mild facial acne pre- 
sented higher scores and therefore better quality of life than those with moderate facial acne. ${ }^{20}$ The association between HRQoL questionnaire scores and acne severity is still controversial, according to studies involving specific instruments, which observed that HRQoL evaluation was more consistently correlated with the severity perceived by the subject than with that described by the investigator. ${ }^{20}$ Some studies have documented a significant correlation, while others have reported none or weak correlations. ${ }^{18,22,23,25,35}$ Our findings support the hypothesis that, even for subjects with mild acne, the disease may undermine their selfconfidence, limit public appearances, and impair family and work relationships. ${ }^{36}$

In accordance with some studies, the results of Acne-QoL-Br validity demonstrated a negative correlation between the scores and how long the subject has had acne in role-emotional and acne symptoms domains, and a marginal correlation for other domains, i.e., subjects with shorter duration experienced better quality of life..$^{29}$ Layton et al reported that women, mainly those who have had acne for more than ten years, presented higher level of compromise in HRQoL as assessed by APSEA. ${ }^{22}$ In addition, in a cohort study with 867 subjects followed up for two years, Tan et al proved that subjects with the highest levels of compromise on quality of life evaluated by the Acne-QoL were those who had had facial acne for more than five years. ${ }^{37}$

The correlations of Acne-QoL-Br domain scores between themselves and with total Acne-QoL-Br score reinforce the questionnaire unity and keep its multidimensional characteristic as a HRQoL tool. The association of role-social and self-perception domains with total score confirmed the observation of a common phenomenon among subjects with facial acne, which is their great concern for their self-image and appearance. By expressing greater concern for self-image than for work, family or school environment relationships, subjects ratify the intuitive reasoning that facial acne creates a negative impact and that they feel embarrassed in their routine activities. ${ }^{5,10}$ We observed that the aspects addressed in the self-perception domain caused negative impact on those related to public appearance, getting known, and living with other people, which are inferences drawn in the rolesocial domain..$^{35}$ This corroborates the positive correlation between the two domains, indicating that they should have contributed significantly for instrument construction, and validates the hypothesis that they yielded the expected measures.

The use of a combination of generic and specific instruments is recommended to reiterate and/or complement the level of compromise in several dimensions. Due to the absence of specific question- naires about acne validated in Brazilian-Portuguese, the version of a generic questionnaire (the BrazilianPortuguese version of the SF-36) was used to verify Acne-QoL-Br validity. SF-36 measurement properties were evaluated by different acne studies and different populations as described by Both et al, reiterating its sensibility to identify quality of life compromise. ${ }^{38}$

As facial acne lesions are apparent, a certain degree of social discomfort may be embedded in this context. This supports the hypothesis that, even in subjects with mild acne, the disease may undermine their self-confidence, limit their public appearances, and impair their family and work relationships. ${ }^{8}$ The correlation between all Acne-QoL-Br domains and the SF-36 role-social domain, along with the correlations of Acne-QoL-Br self-perception and social domains with SF-36 mental health, corroborate the findings described by a case-control survey. ${ }^{15} \mathrm{~A}$ study comprising 111 subjects with facial acne showed that the most compromised SF-36 domains were role-social and mental health, while the role-emotional domain presented some alteration when the patient was followed up during one year. ${ }^{14}$ The mental health scores were worse than those recorded in diseases like asthma, epilepsy, diabetes, backache and arthritis. ${ }^{14}$ A casecontrol study demonstrated that subjects with facial acne, according to the United Kingdom Sickness Impact Profile (UKSIP), felt a greater psychosocial impact than groups without acne on psychological, social functioning, and functional capacity domains. ${ }^{35}$

The statement that acne subjects do not consider themselves sick was reaffirmed in this study by the absence of correlation between Acne-QoL-Br and general health, physical and bodily pain dimensions included in the SF-36. This demonstrates that general health status was preserved, as observed in other studies. ${ }^{14,15}$

Unlikely, no correlations were perceived either between Acne-Qol-Br and SF-36 role-emotional domains and Acne-QoL-Br role-emotional and SF-36 mental health domains in this study. These findings corroborate the controversies about the association between psychological alterations and acne, which has been extensively discussed by several authors. However, the absence of relevant longitudinal studies establishing the causal relationship between these aspects has stirred up the controversy. ${ }^{37}$

Although Aktan et al analysed 2,657 Turkish students, no difference between acne and control groups was found as far as traces of anxiety and depression were concerned.$^{32}$ It should be pointed out that authors chose the less sensitive scale, the Hospital Anxiety and Depression Scale (HAD), to assess mental health alterations among teenagers. This scale is rarely used for patients assisted at psychiatric clinics. In the 1990s, Gupta et al, by using the HAD, and Kellet et al, by 
using the Carroll Rating Scale for Depression (CRSD), observed that acne subjects had more serious symptoms of anxiety and depression than patients with alopecia areata, atopic dermatitis, psoriasis, and the normal population. ${ }^{25,39}$ In the U.K., Smithard et al evaluated 317 adolescents with acne aged from 14 to 16 years, standardizing subjects' age and using a scale called Strengths and Difficulties Questionnaire (SQD), which evaluates mental health. Results pointed out a prevalence of alterations twice more substantial in the emotional subscale for acne subjects. ${ }^{9}$

According to the complex and multidimensional concept of quality of life, an improvement in psychosocial well-being should be considered a parameter as fundamental as absence of disease. ${ }^{40,41,42}$

This study proposes that the general physician or specialist should try to identify which quality of life dimensions are compromised in facial acne subjects. Traces of minor mental disorders may also be perceived, thus facilitating the understanding of how acne affects mental health.

The evaluation of quality of life may be based on the use of just one question or objective and of standardized questionnaires. These may sort out patients either as time passes by or by taking into consideration whether they have other diseases. It is also possible to predict patient outcomes and evaluate treatment efficacy. ${ }^{43}$ HRQoL scales stem from the necessity to turn "subjective perception into an objective measurement", motivated by the discrepancy between specialist evaluation and patient perception of disease severity. ${ }^{44,45}$ However, it is important to mention that by using these instruments one may not generalize the quality of life perception based only on scores. As some studies highlight, if a compromise in role-social is detected by just one instrument, this information may not necessarily reflect an objective opinion about subject's level of quality of life. ${ }^{28,43,45}$

Acne patients should receive effective and early treatment as improvement in quality of life after ther- apy occurs relevantly and substantially, as demonstrated by various studies using specific instruments. ${ }^{17,37,46,47,48}$ Disease-specific instruments for dermatosis acquire a special meaning because they report in a peculiar way the main perspective related to the harm inflicted on quality of life, including psychosocial and functional dimensions. Nevertheless, it is important to highlight that even certain generic instruments, such as SF-36, are able to detect alterations in quality of life among patients with facial acne. . $^{35,49}$

The physician's decision concerning therapeutic intervention must be based on clinical parameters, such as acne severity and extension, and may not be invalidated by the use of quality of life indicators per se. It is of key importance to consider subject's perception concerning facial acne and the changes in wellbeing as complementary criteria.

The lack of correlation between facial acne severity and Acne-QoL-Br scores observed in this study suggests that patients' perception of their disease may be considered in acne evaluation and treatment.

The limitations of this study are: passive search for subjects with facial acne and lack of analysis of other measurement properties such as responsiveness and degree of questionnaire interpretation.

\section{CONCLUSION}

In summary, this study was able to establish that Acne-QoL-Br is a reliable and valid outcome measure available and applicable in the Brazilian context and a useful instrument to assess HRQoL in subjects with facial acne. These aspects include Brazil in the scenario of studies of HRQoL related to acne. It is important that more reports using that questionnaire, as well as clinical trials, should be carried out in order to consolidate Acne-QoL-Br validity and to evaluate its responsiveness and treatment outcomes in patients with facial acne. $\square$ 


\section{REFERENCES}

1. Lupi 0 , Nunes $\mathrm{S}$, Gomes Neto A, Péricles C. Doenças dermatológicas no Brasil: perfil epidemiológico e atitudinal. An Bras Dermatol. 2010;85:S1-20.

2. Hassun KM. Acne: etiopathogenesis. An Bras Dermatol. 2000;75:7-15

3. Costa A, Alchorne MMA, Goldschmidt MCB. Etiopathogenic features of acne vulgaris. An Bras Dermatol. 2008;83:451-9.

4. Schmitt JV, Masuda PY, Miot HA. Acne in women: clinical patterns in different agegroups. An Bras Dermatol. 2009;84:349-54.

5. Lasek RJ, Chren MM.Acne vulgaris and the quality of life of adult dermatology patients. Arch Dermatol. 1998:134:454-8.

6. Uzun 0, Başoğlu C, Akar A, Cansever A, Ozşahin A, Cetin M,et al. Body dysmorphic disorder in patients with acne. Compr Psychiatry. 2003 Sep-0ct;44:415-9.

7. Mulder MM, Sigurdsson V, van Zuuren EJ, Klaassen EJ, Faber JA, de Wit JB, et al. Psychosocial impact of acne vulgaris: evaluation of the relation between a change in clinical acne severity and psychosocial state. Dermatology. 2001;203:124-30.

8. Wu SF, Kinder BN, Trunnell TN, Fulton JE. Role of anxiety and anger in acne patients: a relationship with the severity of the disorder. J Am Acad Dermatol. 1988;18:325-33.

9. Smithard A, Glazebrook C, Williams HC. Acne prevalence, knowledge about acne and psychological morbidity in mid-adolescence: a community-based study. $\mathrm{Br}$ Dermatol. 2001;145:274-9.

10. Tan JK, Vasey K, Fung KY. Beliefs and perceptions of patients with acne. J Am Acad Dermatol. 2001;44:439-45

11. Yazici K, Baz K, Yazici AE, Köktürk A, Tot S, Demirseren D,et al. Disease-specific quality of life is associated with anxiety and depression in patients with acne. J Eur Acad Dermatol Venereol. 2004;18:435-9.

12. Ribas J, Oliveira CMPB, Ribeiro JCS. Acne vulgar e bem-estar em acadêmicos de medicina. An Bras Dermatol. 2008; 83:520-5.

13. Halvorsen JA, Stern RS, Dalgard F, Thoresen M, Bjertness E, Lien L. Suicidal ideation, mental health problems and social impairment are increased in adolescents with acne: a population-based study. J Invest Dermatol. 2011;131:363-70.

14. Newton JN, Mallon E, Klassen A, Ryan TJ, Finlay AY. The effectiveness of acne treatment: an assessment by patients of the outcome of therapy. $\mathrm{Br} J$ Dermatol. 1997;137:563-7.

15. Mallon E, Newton JN, Klassen A, Stewart-Brown SL, Ryan TJ, Finlay AY. The quality of life in acne: a comparison with general medical conditions using generic questionnaires. Br J Dermatol. 1999;140:672-6.

16. Patrick DL, Deyo RA. Generic and disease-specific measures in assessing health status and quality of life. Med Care. 1989;27:S217-32.

17. Klassen AF, Newton JN, Mallon E. Measuring quality of life in people referred for specialist care of acne: comparing generic and disease-specific measures. J Am Acad Dermatol. 2000;43:229-33.

18. Motley RJ, Finlay AY. How much disability is caused by acne? Clin Exp Dermatol. 1989;14:194-8.

19. Girman CJ, Hartmaier S, Thiboutot D, Johnson J, Barber B, DeMuro-Mercon C, et al. Evaluating health-related quality of life in patients with facial acne: development of a self-administered questionnaire for clinical trials. Qual Life Res. 1996;5:481-90.

20. Martin AR, Lookingbill DP, Botek A, Light J, Thiboutot D, Girman CJ. Health-related quality of life among patients with facial acne- assessment of a new acne-specific questionnaire. Clin Exp Dermatol. 2001;26:380-5

21. Fehnel SE, McLeod LD, Brandman J, Arbit DI, McLaughlin-Miley CJ, Coombs JH, et al. Responsiveness of the acne-specific quality of life questionnaire (Acne-Qol) to treatment for acne vulgaris in placebo-controlled clinical trials. Qual Life Res. 2002;11:809-16.

22. Layton AM, Seukeran D, Cunliffe WJ. Scarred for life? Dermatology. 1997;195:15-21

23. Anderson RT, Rajagopalan R. Development and validation of a quality of life instrument for cutaneous diseases. J Am Acad Dermatol. 1997;37:41-50.

24. Anderson R, Rajagopalan R. Responsiveness of the dermatology-specific quality of life (DSQL) instrument to treatment for acne vulgaris in a placebo-controlled clinical trial. Qual Life Res. 1998;7:723-34.

25. Gupta MA, Johnson AM, Gupta AK. The development of an acne quality of life scale: reliability, validity, and relation to subjective acne severity in mild to moderate acne vulgaris. Acta Derm Venereol. 1998;78:451-6.

26. Kurwa HA, Finlay AY. Dermatology in-patient management greatly improves life quality. Br J Dermatol. 1995;133:575-8.

27. de Tiedra AG, Mercadal J, Badía X, Mascaró JM, Lozano R. A method to select an instrument for measurement of HRQOL for cross-cultural adaptation applied to dermatology. Pharmacoeconomics. 1998;14:405-22.
28. Le Cleach L, Chassany O, Levy A, Wolkenstein P, Chosidow O. Poor reporting of quality of life outcomes in dermatology randomized controlled clinical trials. Dermatology. 2008;216:46-55

29. Lehmann HP, Robinson KA, Andrews JS, Holloway V, Goodman SN. Acne therapy: a methodologic review. J Am Acad Dermatol. 2002;47:231-40.

30. Scientific Advisory Committee of the Medical Outcomes Trust. Assessing health status and quality of life instruments: attributes and review criteria. Qual Life Res. 2002:11:193-205

31. Pochi PE, Shalita AR, Strauss JS, Webster SB, Cunliffe WJ, Katz HI, et al. Report of the Consensus Conference on Acne Classification. Washington, D.C.March 24 and 25, 1990. J Am Acad Dermatol. 1991:24:495-500.

32. Aktan S, Ozmen E, Sanli B. Anxiety, depression and nature of acne vulgaris in adolescents. Int J Dermatol. 2000;39:354-7.

33. Daniel F, Dreno B, Poli F, Auffret N, Beylot C, Bodokh I,et al. Epidémiologie descriptive de l'acné dans la population scolarisée en France métropolitaine pedant l'automne 1996. Ann Dermatol Venereol. 2000;127:273-8.

34. Dreno B, Finlay AY, Nocera T, Verrière F, Taïeb C, Myon E. The cardiff acne disability index: cultural and linguistic validation in french. Dermatology. 2004;208:104-8.

35. Salek MS, Khan GK, Finlay AY. Questionnaire techniques in assessing acne handicap: reliability and validity study. Qual Life Res. 1996;5:131-8.

36. Gollnick H, Cunliffe W, Berson D, Dreno B, Finlay A, Leyden JJ,et al. Management of acne: a report from a global alliance to improve outcomes in acne. J Am Acad Dermatol. 2003;49:S1-37

37. Tan JK, Li Y, Fung K, Gupta AK, Thomas DR, Sapra S,et al. Divergence of demographic factors associated with clinical severity compared with quality of life impact in acne. J Cutan Med Surg. 2008:12:235-42.

38. Both H, Essink-Bot ML, Busschbach J, Nijsten T. Critical review of generic and dermatology-specific health-related quality of life instruments. J Invest Dermatol. 2007:127:2726-39.

39. Kellett SC, Gawkrodger DJ. The psychological and emotional impact of acne and effect of treatment with isotretinoin. Br J Dermatol. 1999;140:273-82.

40. Who. Int [homepage on the Internet]. World Health Organization. Measuring Quality of Life. The World Health Organization Quality of Life Instruments. 1997 [cited 2009 Nov 29].Available from: http://www.who.int/entity/mental_health/media/68.pdf.

41. Coppini $R$, Jorge MR. Qualidade de vida e transtornos mentais graves. In: Diniz DP, Schor N, editores. Qualidade de vida. Guias de Medicina Ambulatorial e Hospitalar da UNIFESP / Escola Paulista de Medicina. São Paulo: Manole; 2006. p. 65-78.

42. Fried RG, Wechsler A. Psychological problems in the acne patient. Dermatol Ther 2006:19:237-40.

43. Berlim MT, Fleck MP. "Quality of life": a brand new concept for research and practice in psychiatry. Rev Bras Psiquiatr. 2003;25:249-52.

44. Testa MA, Simonson DC. Assessment of quality-of-life outcomes. N Engl J Med. 1996;334:835-40

45. Blay SJ, Merlin MS. Desenho e metodologia de pesquisa em qualidade de vida. In: Diniz DP, Schor N, editores. Qualidade de vida. Guias de Medicina Ambulatorial e Hospitalar da UNIFESP / Escola Paulista de Medicina. São Paulo: Manole; 2006. p.19-30.

46. Grosshans E, Marks R, Mascaro JM, Torras H, Meynadier J, Alirezai M, et al. Evaluation of clinical efficacy and safety of adapalene $0.1 \%$ gel versus tretinoin $0.025 \%$ gel in the treatment of acne vulgaris with particular reference of the onset of action and impact on quality of life. Br J Dermatol. 1998;139:26-33.

47. Finlay AY. Quality of life assessments in dermatology. Semin Cutan Med Surg. 1998:17:291-6.

48. Finlay AY. Quality of life indices. Indian J Dermatol Venereol Leprol. 2004:70:143-8.

49. $\mathrm{Ng} \mathrm{CH}$, Tam MM, Celi E, Tate B, Schweitzer I. Prospective study of depressive symptoms and quality of life in acne vulgaris patients treated with isotretinoin compared to antibiotic and topical therapy.Australas J Dermatol. 2002;43:262-8.
MAILING ADDRESS:
Jane Tomimori
Department of Dermatology - Universidade Federal de
São Paulo / UNIFESP
Rua Borges Lagoa, 508
04038-001 - São Paulo,SP
E-mail: jane.tomimori@unifesp.br;
cristhineslk@yahoo.com.br

How to cite this article:Kamamoto CSL, Hassun KM, Bagatin E, Tomimori J.Acne-specific quality of life questionnaire (Acne-QoL): translation, cultural adaptation and validation into Brazilian-Portuguese language.An Bras Dermatol. 2014;89(1):83-90. 